British Journal of Education, Society \&
Behavioural Science
$12(4): \begin{gathered}1-10,2016, \text { Article no.BJESBS.22086 } \\ \text { ISSN: 2278-0998 }\end{gathered}$
SCIENCEDOMAIN international
Www.sciencedomain.org

\title{
Invisible Work: Gendered Examples from Three Finnish Call Centres
}

\author{
Tuija Koivunen $^{1^{\star}}$ \\ ${ }^{1}$ University of Tampere, Tampere, Finland. \\ Author's contribution \\ The sole author designed, analyzed and interpreted and prepared the manuscript. \\ Article Information \\ DOI: 10.9734/BJESBS/2016/22086 \\ Editor(s): \\ (1) Madine Vander Plaat, Department of Sociology and Criminology, Saint Mary's University, Canada. \\ Reviewers: \\ (1) Bakky Ngozi Adirika, Nnamdi Azikiwe University, Awka, Nigeria. \\ (2) John Walsh, Shinawatra University, Thailand. \\ Complete Peer review History: http://sciencedomain.org/review-history/11893
}

Original Research Article

Received $17^{\text {th }}$ September 2015

Accepted $8^{\text {th }}$ October 2015

Published $19^{\text {th }}$ October 2015

\section{ABSTRACT}

Aims: This article examines invisible work tasks in the work organizations of call centres. The aim is to analyze what kinds of invisible work tasks there are and, moreover, to find out how these arrangements are divided according to employees' gender and position in the work organization.

Study Design: The empirical evidence is based on ethnographic research in three call centre organizations in Finland. The semi-structured interviews were the main research technique in the field. Researchers have only seldom focused on invisible work tasks as the starting point of analysis, even though this could give otherwise unattainable insights into the ways in which work at large is organized, especially in relation to gender.

Conclusion: The analysis indicates that the invisible work tasks in call centres mostly follow the same gendered pattern as the formal work tasks.

Keywords: Invisible work; informal work; gender; call centres; ethnographic approach.

\section{INTRODUCTION}

The focus of this article is on invisible work tasks in the work organizations of call centres. Invisible work refers to work tasks which are often unrecognized, unvalued and unpaid, and therefore one aspect of equality in work life. Such work is done in countless workplaces, and 
usually invisible work becomes visible only when it is left undone. Researchers have seldom focused on invisible work tasks as the starting point of analysis, even though this could give them otherwise unattainable insights into the ways in which work at large is organized, especially in relation to gender.

The aim was to ask, what kinds of invisible work tasks there were in the work organizations, and, in addition, to find out how the arrangements of invisible work were divided according to employees' gender and their position in the work organizations. The focus was on the invisible tasks that benefit employees and the social community of work, and sometimes also the business of the firm. The analysis also included invisible tasks related to our ethnographic fieldwork in the firms. By doing this, I brought into focus the somewhat ignored aspect of invisible and often informal tasks in the workplaces. The empirical evidence was produced in three call centre organizations in Finland.

Invisible work refers to work, which is not recognized being done, or that it is of value. It has been suggested [1] that work may be invisible because the place of work is hidden, the employees who do the work are invisible or the work itself is unseen. Several of these forms of work's invisibility may occur simultaneously.

The call centre business in general is rather unknown and invisible to customers in Finland, although this situation is slowly changing. Call centre work is background work done in invisible places, quite similarly as the highly skilled behind-the-scenes work of, for example, reference librarians [1,2]. Call centre work is literally invisible to customers who usually do not visit call centre offices and cannot see customer service agents working there. Moreover, Finnish customers do not necessary realize that they are talking with call centre agents instead of the employees of the firm they do business with. This kind of hiding of the call centre operation is usually done deliberately at the request of the corporate client when the assignment is outsourced to an external call centre [3] as is the case in this study's call centres.

Moreover, work may be invisible because invisible people, for example domestics, do it [1]. Work done at invisible places, such as homes, by invisible people, may not be recognized as work at all, and therefore it is in double jeopardy to be not seen [4]. Similarly, there are invisible people in most of the work organizations, working as secretaries, janitors, cleaners and postmen. Their work may be taken for granted while the employees are not seen. Call centres are an important form of front-line service work: that is, jobs involving an interaction between the agents and customers, but still the employees are invisible. Culturally call centre work is considered as women's work $[3,5,6]$, which also enhances its invisibility.

In addition, work may be invisible because of the nature of it. Two different types of invisible work tasks has been pointed out [1]. The first are defined as routine or manual work but actually require considerable problem solving and knowledge. One example is the work of telephone operators, whose work is heard but not literally seen. Part of the service work in call centres appears as routine work, but involve various working skills. Secondly, informal work processes that are not part of anybody's job description but are crucial for the collective functioning of the workplace $[1,2]$. This kind of work is usually both invisible and informal, and therefore in double jeopardy being not recognized. Not all invisible work is informal in nature, although in many cases it is. Similarly, visible work may be either informal or formal.

Formal work - or organization, as it has also been called - refers to the activities and processes related to work, rules such as policies, procedures and regulations as well as the actual work tasks and activities related to these. In other words, the activities of the formal work are more or less required at work. In contrast, informal work, or organization, is more nuanced than the formal organization and it refers to activities and processes not necessarily directly related to work. Such are, for example, attitudes and beliefs, gestures of goodwill and other interaction among the social community of work. In other words, informal tasks are not directly related to making profit, but they may enhance profit making, and informal activities may support work even if they are not directly related to it. Such activities are not required in work but conducted on free will and still possible to carry out during work time at the workplace. Furthermore, informal tasks do not usually include to anybody's job description and the employees are not paid of doing them $[7,8]$.

The distinction between the formal and the informal work of the employees goes back to the Hawthorne studies conducted at the Hawthorne plant in the US in the late 1920s and early 1930s. Formal work was understood to refer to those 
patterns of interaction prescribed by the company rules, regulations and policies. In contrast, informal work referred to the personal interrelations of the employees which were not represented by the formal work. The researchers used this distinction between formal and informal work to suggest that workers were not motivated by economic or other "rational" interests such as wages. Hence, the effect of workers' informal work on productivity was emphasized [9-11].

The division between the formal and informal work was developed in relation to industrial work. Taking in account the essentially different nature of service work in call centres, the clear-cut division between the formal and informal work is not always possible to make. In some instances of work, the informal tasks intertwine with the formal tasks, and they enhance each other. Informal work practices may be a crucial means to tackle the day-to-day problems in work, as it is noted to be in gold miners' work [12]. It is noteworthy that gender cannot be situated in one or the other of these layers of work organizations but is relevant in relation to both of them. Thus, this article follows the idea that gender is a property of organizations, not just individuals $[13,14]$.

It has been noted that the new forms of work have started to resemble traditional domestic work in their practical management of boundless and endless, never completed, mostly immaterial tasks and chores. Furthermore, new work is not characterized by a sequence of tasks or a separation of spaces, but rather by chronological intermingling and spatial overlapping [15]. Moreover, emotions have become important characteristics of new work, and one form of unpaid and often unrecognized invisible work in service work still is employees' emotional labour, the management of one's own feelings. It is often required, but seldom paid, valued or appreciated [16]. It is claimed that emotional labour differentiates men's work from women's work in the sense that women are more often required to display emotional labour than men. For example, female flight attendants find emotional labour more demanding than men, and thus unwelcome heterosexualizing propositions make emotional labour still more onerous for women [16-18.] Emotional labour is a form of work, which is not mentioned in the categorization of invisible work [1], although it is, together with other forms of embodied labour, rather largely expected form of invisible work.

\section{RESEARCH MATERIALS AND METHODS}

The ethnographic research material to which I refer includes semi-structured interviews, nonparticipant observations, digital photos and documents. However, the analysis concentrated on interviews and field notes based on observations while the rest of the research data were considered as background material. In other words, photos and documents informed the analysis of interviews and field notes, which were considered as the key source of data. The data were drawn from a larger study on three call centre firms in Finland [3]. The research data were produced in three case study call centres, which utilized different types of labour force in terms of the employees' age, gender, length of employment in the firm and educational background. The interviews were not aimed for studying informal tasks but to investigate genderrelated practices in the work organizations at large.

The empirical research material consisted of 54 interviews with call centre workers and managers. The interview questions included the themes of gender divisions at the workplace; social interaction with co-workers and managers; the social community of work and potential conflicts and disagreements at work. These themes allowed the interviewees to talk about issues that I conceptualize as informal tasks. Moreover, the field notes contained descriptions of instances, tasks and practices that were found as informal in nature, such as coffee room practices, a gathering with mulled wine, employees' discussions during the workday and short time slots just before and after the interviews.

The ethnographic research data was mainly produced by me but also by my senior colleague Päivi Korvajärvi. We both conducted interviews and observations in all three case study organizations. In general, we were welcomed and granted full access to the workplaces, although one of the call centres was an exception in this. We were not allowed to access the staff room or the actual working space of the customer service agents, and consequently, to observe the agents' customer service work. The practice was justified with arguments of the organization's privacy protection policy, which guaranteed full privacy to the corporate clients. We conducted all the interviews in the employees' offices, in empty offices or in meeting 
rooms during regular working hours. The interviews generally lasted between fifteen and ninety minutes, averaging about sixty minutes overall. I have changed the participants' actual names to pseudonyms. For the sake of convenience, I call the work organizations with the pseudonyms Purple, Green and Blue.

What distinguished all three case study organizations Purple, Green and Blue from each other were their size, ownership, location, work assignments and labour force. What was common to the firms was that they were independent subcontractor firms to which several corporate clients had outsourced a share of their customer service and telemarketing. Another common point was that there were more women than men working on the office floor level. At the levels of middle management and top management, the gender division varied among the work organizations. Thus, the hierarchical gender segregation which refers to the gender differences in the organizational hierarchy varied among the call centres.

When it came to the analysis of the interviews and observations, I followed the same logic that was suggested [19] as the initial stages of ethnographic analysis. I firstly identified the instances which are related, according to my interpretation, to invisible work tasks. This involved doing a systematic thematic reading of the data over and over again [20]. In practice, I read the research data through the themes of invisible work tasks and informal side of the work organizations. During the reading, the content of these themes become more precise. The second phase of analysis involved analysis of the instances where gender was mentioned in the research data. More to the point, the call centre employees talked about doings and characteristics of women and men but did not talk about gender as such [3]. Respectively, I have also teased out gender from other pieces of the data where gender is present on a subtler level than in reference to women and men. Gender is, then, a conceptualization I adopted from the theoretical frame of the article.

The last stage of the analysis was the writing of the research report $[21,22]$. Writing is a way of knowing - a method of discovery and analysis with which it is possible to discover new aspects of the topic and the writer's relationship to it $[23,24]$. At this stage, the empirical research was complemented by secondary literature and the findings were related to previous studies and theoretical discussions. Moreover, writing binds the pieces of analysis together to a coherent research report and draws the study back to the original context of the work organizations.

The article is based on the analysis of practices, which focused on what the people do in their everyday lives and how the social order and institutions are constituted [25]. It has been argued that such approach is particularly useful in studying gender in organizational phenomena because gender is constantly negotiated and redefined in everyday practices through which the individuals interact. In other words, women and men do gender and contribute to the construction of gender identities when they carry out and are carried out by the practices [25,26]. Thus, the approach of doing gender, where gender is understood as doing and practicing it instead of being a woman or a man $[27,28]$, was adopted.

The concept of practicing gender was utilized as an analytical tool, and by doing so it was possible to focus on rather small, everyday interactions between individuals. The concept was originally elaborated by Patricia Yancey Martin and it points to "doing gender" through interaction. Martin [26] conceptually distinguishes the practicing of gender from gendering practices. In the context of work, gendering practices refer most of all to gender divisions of labour and cultural understandings about women's and men's work. Practicing gender refers to the literal saying or doing of gender, and accordingly to exercising agency in real time and space. It is often rapid fire, directional, time bound and informed by minimal awareness, yet sometimes practiced intentionally. Practicing gender, or more to the point practicing femininity and masculinity, is largely unreflective but also unavoidable behavior since our activities and being are interpreted on the grounds of our gender. Nevertheless, the interpretations do not have to be congruent with our gender. Consequently, the article enables a better understanding of the gender divisions of work.

\section{RESULTS AND DISCUSSION}

\subsection{Staff Room Activities}

From the beginning of our fieldwork in the work organizations it became obvious that something very special concentrated on kitchens and staff rooms. They are the private spheres of public workplaces [29]. I argue that in those places intersect what has been called [1] invisible work done in invisible places and informal work 
processes, which are not part of anybody's job description. A particular task in staff rooms is making coffee for the breaks. Coffee has an important role in the Finnish society at large, and also in workplaces. Finns are among the biggest coffee consumers worldwide, and the statutory breaks at work are called coffee breaks, and staff rooms are called coffee rooms. Consequently, drinking coffee is a norm, and drinking tea, for example, is not.

When I first visited Purple in order to interview the male managing director, there was a coffee cup waiting for me. I was not asked if I drink coffee or not, and therefore I had to let the managing director to know that I prefer tea. He replaced the coffee cup with a teacup and served me tea instead of delegating the task to somebody else. I was embarrassed by the fuss my dislike to coffee was causing. Moreover, the situation was full of hidden cultural meanings he, a man and a managing director offering me his hospitality in the form of coffee, and me, a woman and a visiting researcher, declining his hospitality and asking for tea.

In Blue there was also an incident concerning coffee in the beginning of our fieldwork. We first arrived there, my colleague and I, with an intention to interview the male CEO and the male call centre manager. Before we started, they offered coffee to us. However, neither of us drinks coffee. In order to serve tea, the call centre manager used his mobile phone to call a female team leader who worked upstairs. He tried to ask her, without us noticing it, where the tea bags were. As in Purple, also in Blue it was unexpected that the visitors did not drink coffee. At that time the situation felt quite amusing: a male call centre manager was trying to serve tea to two female researchers, but he had to phone to a female team leader and ask for help.

Quite similarly, Ikonen and Ojala [30] have described how an interviewee served warm sausage sandwiches to the vegetarian researcher in her home. The researcher ate the sandwiches because she felt that it would have been too rude to decline the offer. I was not able to behave in such a polite way because my dislike is so strong that it is simply impossible for me to drink coffee. However, these fieldwork incidences set the tone of the analysis for their part. Moreover, they informed the researcher of the ways in which such surprising situations are handled in the work organizations, although these particular situations would not have occurred without the researcher entering the field.

In the third workplace, Green, we were not welcomed to the staff room where the kitchen facilities were. Nevertheless, we were told about the invisible tasks carried out there. According to the interviewees, the organizational housekeeping was associated with women and was expected to be done by female employees. Moreover, age was a crucial factor in relation to these informal tasks, and, for example, one of the old-timer agents expressed the division based on age as 'the kindergarten department and the rest of us.' Hence, a couple of the middle-aged or older women took care of coffee making for the statutory breaks and for loading the dishwasher afterwards. They looked after assorting the trash for recycling and took care of the lockers and coffee rooms and also took responsibility for arranging social events and exercise in leisure time. However, it cannot be told apart if these women were expected to do organizational housekeeping because of their age or their relatively long work history, because these two can go hand in hand.

The informal tasks in Green's staff room could have been organized in other ways and, for example, could be arranged in shifts between all the agents regardless of them being women or men. Instead, these middle-aged agents were expressing organizational motherhood or housewifery at work by doing these tasks which are sometimes considered as voluntary. Thus, the predominant atmosphere at the workplace encouraged these female employees to act in accordance with the gendered expectations. To put it differently, the informal tasks conformed to the stereotypes of women as caring, sociable and skilled at household tasks.

In contrast to Green, the informal tasks in Purple's kitchen were done without a collective organization of rotas or suchlike. Presumably, a kitchen rota would have been difficult to organize because the majority of the telemarketers had personal preferences in working times and, consequently, they did not work five days a week. Subsequently, the common everyday tasks were done individually. Everybody washed their own dishes and cleaned up after themselves. The two female sales managers' task was to make coffee ready before the breaks. Presumably, this was in order to avoid interrupting the profitable work of the telemarketers. However, one of the two female sales managers, Asta, pointed out that she does 
not always remember to make the coffee in her turn.

Everybody knows me, and when I'm in the evening shift for example, I should make coffee, and I don't, ever. "Asta is doing the evening shift, so there is no coffee." I don't remember it when I'm in the middle of doing a hundred things at a time, and good heavens, its six o'clock and I haven't made coffee.

Making coffee was included in Asta's work duties, but because she frequently forgot to do it, the task turned even more invisible. Asta's interview does not tell who eventually makes coffee instead of Asta, or are the employees left complete without coffee. My interpretation is that the sales managers, particularly Asta, did not consider making coffee or other organizational housekeeping tasks as degrading, but they were preoccupied with their mundane work.

In Blue, taking care of the kitchen was divided into rotating shifts which lasted for one week at a time. The shift included making coffee before the breaks and clearing the coffee room afterwards, loading and emptying the dish washer, switching the lights off and locking the kitchen door after the work day. As far as I can tell, there were no gender-related arrangements involved in the kitchen shifts and the employees did not comment against the practice. The only complain was the division of the kitchen shifts between the two teams of different sizes.

The employees' statutory coffee breaks were staggered and, at least when I was present, the women were sitting on one side of the table and the men on the other. During lunch and coffee breaks, informal discussion was propelled by gender roles that I would describe as rather conventional in the sense that they were based on women's and men's different spheres of responsibilities. For example, a group of women were once discussing in a humorous tone how helpless their spouses were and how the men could not find their socks when they were getting dressed. This coffee break discussion is an example of how private life came to the workplace. Accordingly, work organizations are often replete with displays of private and unspoken heterosexuality, such as wedding rings, pictures of spouses and heterosexual couples, together with a more general heterosexual aesthetic which frames bodily appearance and symbolic interaction [31]. While domestic affairs and family relations were a topic in these discussions, at the same time the tone for discussing about gender differences and gender relations was set.

Carrying out these invisible tasks on the employees' working time probably has an effect on their wages, since their wages is based on bonuses and the less they are working, the smaller their bonuses are. If the employees' carried out the tasks on breaks, the time was taken away from their recreational time. The motivation to carry out the tasks cannot be identified, but it has been argued [29] that work done in private spheres is something you want to do, something that is motivated by love and care. However, the rotating shifts are an exception to this, because they obligate the employees to perform their share of the tasks.

\subsection{Informal Events}

In work organizations, there are also informal events, which concentrate on social interaction, fun and games, and recreation. The organization and arrangements of these events are usually included to someone's work load. In Nardi and Engeström's [1] classification, work tasks related to informal events are invisible in the sense that they are work considered as routine, but may require more work in general and especially with details, problem solving and organizing skills than presumed beforehand. Moreover, these tasks are usually not part of anybody's job description.

In Purple, events that could be interpreted as informal were mostly trips, Christmas parties and other happenings. The trips abroad and events in general were visible in everyday physical organization since the photos taken there were an important part of the office decoration. However, the initiative and resources to these activities came from the management and in this sense, these were organizational events although informal in nature. Asta was the main organizer of all the events, which she obviously enjoyed.

Well, a year ago we had a red night, it was really nice and there were a lot of participants. Everyone had to wear something red. I always like to organize such things. And then everything in here was red and the food was red, we had beetrootmince casserole and red dessert. The drinks were red too, there was red wine and then red soda and really everything was red. 
When Asta was describing this red night and other events and parties she has organized to me she was thrilled. Although Asta enjoyed organizing events, she was very busy and even stressed out with all the work responsibilities she had. Yet, she welcomed the planning of the informal events as an exciting change in her work.

What is more, during one of my fieldwork periods in Purple, Asta organized a gathering with mulled wine to which I, too, was invited. She also cleaned up everything afterwards. All the employees together with the owners of the family business were enjoying mulled wine with or without alcohol and some Christmassy snacks. The owners' son, the managing director, did all the official talking to the employees, but I got the impression that her parents' presence in this gathering was very important to the work community. The gathering was relatively short, as were all the breaks we attended in Purple, and soon all the telemarketers were back in their offices making calls to the customers.

In Blue, every other month the employees had the possibility to take part in a recreational day that Blue organized and covered with a couple of euro for every employee's activity and the employees paid the rest themselves. They had gone to the theatre, bowling, to a guided lesson of Nordic walking, on a cycling trip, and took part in an ice fishing contest. The actual person who organized these activities was not working in the office where the fieldwork was conducted, and therefore she or he was not interviewed. The recreational activity took place during the employees' leisure time which some employees considered as a problem. They thought that the recreational activities should be organized to happen during their workday and for this reason they did not want to participate. Thus, the employer considered recreational days as leisure time activities, while some of the employees considered them more as working time activities.

In Green, the employees had possibility to attend recreational activities during their leisure time with the vouchers their employer offered for them. For the first time in the firm's history it had a female CEO, and she had launched several employee-friendly social practices, such as summer gifts, gifts for the loyal employees who have worked in Green certain number of years, and Christmas parties. The CEO was determined that after a gap of several years, the company would resume its tradition of throwing Christmas parties to the employees. According to her, it simply was a must because the Christmas party was such an important part of the Finnish work culture.

The above described events with their organizing responsibilities blur further the division between formal work and informal work. Although the purpose of such events is good and wellintentioned, it may turn as a burden to a person who has the organizing responsibilities, especially if the responsibilities are not shared and they fell to same person repeatedly. Moreover, attending the call centre events may cause disagreements when, for example, someone needs to stay at work while others may take part in the events. The female sales manager Asta in Purple was an example of this. Quite similarly, Connell [14] found in one of her worksites that when a social event came to be held - a fund-raiser for charity - it was two women who organized it. This is although the planning, organizing and holding the events may be fun and rewarding.

\subsection{Collegial Help and Advising}

Call centre work, or more to the point, emotional labour done in call centres is often emotionally draining. In rapidly changing customer service situations agents and telemarketers need to simultaneously master a lot of details and facts, to interact with customers smoothly and to use technology. In doing all this, the employees often ask help from their colleagues [3,32]. Collegial help and advising is invisible work in the sense that it appears as simple but it requires skills, knowledge and ability to solve problems [1]. Moreover, doing emotional labour or giving collegial help and advising are not included to agents and telemarketers' job description but it is a common everyday practice.

In Green, the social community of work played a central role in supporting the agents in their work tasks. This became especially apparent in the problem situations. When customers asked something that the agent did not know or when there were difficulties with the computer, the agents had to ask for help. In the rapidly changing situations of call centre work, it was difficult for the team leaders to be present and available to the agents all the time and to solve their problems. Therefore, it was convenient and easy to consult someone who was sitting next to you. The agents' workstations were arranged in banks of six and the employees who were working in the same project were placed close to each other. 
In call centre work this type of helping colleagues appeared to be self-evident, but in other jobs and occupations it necessarily is not. Fletcher [13] has studied invisible work - or disappearing acts, as she calls them - of female design engineers' and found, that in their highly masculine work environment it is essential and heroic to solve problems, or at least talk about them, while preventing problems was not seen as real work. In call centre work the emphasis is always on fast and smooth encounter with customers, and therefore it is important to foresee the customers' potential problems.

There are cultural assumptions about what kind of knowledge and tasks are 'natural' to women and men in the work organizations [13]. In the call centres, one gender-related division goes between technical support, including technical knowledge, qualifications and experience as well as an interest in computers, and customer service which includes skills at listening to and empathizing with the customers. Technology is associated with men more often than with women [32,33]. However, in Green the number of female agents was larger than or about the same as that of male agents in the technologyrelated projects. In the interviews it was pointed out that the topics of informal discussions were gendered according to one's interest in information technology. It was said that there were a couple of men whose hobby was information technology, computer games and tuning up computers. Thus, all who had such a hobby were men, but not all men were interested in information technology and computers. For instance, one of the team leaders - he was a student of humanities - explained that the other employees ask him when there were problems with computers:

Henrik: l've noticed that if some agent has some problem with the computer so maybe they prefer to come to me for advice. For some reason they think that I would know computer things better than if they were to go to some woman and ask her. Although it could be the other way round, that the women know more than I do.

In the extract, Henrik describes that he was asked for advice with computers even though he was not very good with technology. This implicates that the assumed technical skills were associated with his gender, not with his interests in technology, his work experience or his education in the humanities. It has also been noted [14,33] that expertise in computer technology is often related to young male employees. Thus, it could be said that in Green, the organizational housekeeping was the expertise of women and the computer technology was the expertise of men. However, the appreciation of these two fields of expertise in our culture is in complete different levels [33].

In Purple, the sales manager Asta was very busy and even stressed out with all the formal and informal work responsibilities she had. 'This is a stressful job, really horrible,' she said in her interview, although she added that she nevertheless liked her job. Moreover, she described her work as very time-consuming and emotionally hard, especially when it included supporting the telemarketers in their private life matters, but also in issues related to their work:

Asta: When you come to this job you are, to tell you the truth, like a cesspit; when everything negative comes to me and I cannot transform myself into register material [the data the telemarketers use when they call customers]. So sometimes you get like, hell no, l'd like to come sometime, let's change places. I say a lot of times that you come to my spot here, come and listen to this. Nothing is ever good. So I go to make calls, I get to close the door behind me and make the calls alone. I'd like to do that sometime, so you wouldn't have to care about anyone else or think about what kind of results you get with what register material, you'd just get to make the call and if they aren't happy with it, so what.

Thus, it is Asta's everyday work and especially her emotional responses to the telemarketers' troubles that stress her out. In other words, the telemarketers' worries increased the workload of the sales managers and Asta, in particular. Both sales managers had their office doors open all day, and they were willing to help the telemarketers whenever they needed assistance or support. This invisible task appeared as 'natural' and unquestioned part of their everyday work, as emotional labour often does.

\section{CONCLUSION}

The invisible tasks in the call centres included organizational housekeeping tasks, such as making coffee before the breaks, clearing the coffee room afterwards, switching the electronic devices and lights off, recycling the trash and general caretaking of the organization's spaces and everybody's comfortableness. Moreover, the invisible tasks consisted of responsibility for 
arranging leisure time social activities such as trips, parties and other events. In addition, advising and helping other employees in problem situations with customers or computers is here considered as invisible work tasks if these are done collegially instead of the channels of hierarchical organization structure. Another invisible task was emotional labour, that is, listening to colleagues' worries and trying to keep them in good mood. Finally, the informal discussions during breaks offer a glimpse of the way in which domestic affairs and family relations were brought to the workplace. These tasks were informal in nature although some of them lubricated the formal side of the work. Nevertheless, the background of these work tasks in the call centres cannot be traced, and therefore we do not now the processes which have led to present situation.

In two of the call centre organizations in which no rota or other arrangement is set for the tasks the invisible tasks tend to pile up on some employees' shoulders. Especially when the organizational housekeeping tasks are in question, the employees who carry them out are more often women than men. This adds to these women's work load at work and reduces the time they can spend on doing their work with commission-based wage. In the interviews, men are not mentioned in relation to any particular invisible tasks, except helping with computer problems. Moreover, age had an effect on the division of invisible tasks especially when there were employees of varying ages working in a call centre. The middle-aged employees took responsibility for carrying out the invisible tasks more often than the younger employees.

On the basis of the analysis the invisible tasks in general seem to follow the same gender pattern as visible and formal tasks in the work organizations. In other words, invisible tasks could be considered as gendering practices [27] which utilize the larger gender order at the workplace and in the society. I have presented the ways in which invisible work tasks are divided according to employees' gender and position in the work organizations of call centres, but, nevertheless, the other part of the dual concept, practicing of gender [27], is not as clearly present in the data. This is more a question of the data then a shortcoming of the dual concept. Moreover, gendering practices of invisible work tasks are also called micro gender division of labour and they illustrate the persistent details in the daily life of the worksites [14]. However, the systematic description and analysis of this micro gender division of labour has been scarce. Invisible work is often invisible for the research, too, although it offers an apt site to concentrate on the unseen side of work and organization. Invisible work also includes the potential for gradually changing the gender order at the workplaces.

\section{CONSENT}

The author declares that oral informed consent was obtained from the participants for publication of this case report.

\section{COMPETING INTERESTS}

Author has declared that no competing interests exist.

\section{REFERENCES}

1. Nardi BA, Engeström YA Web on the Wind: The Structure of Invisible Work. Computer Supported Cooperative Work, 1999; 8:1-2,1-8.

2. Kosny A, MacEachen E. Gendered, Invisible Work in Non-profit Social Service Organizations: Implications for Worker Health and Safety. Gender, Work and Organization. 2010;17:(4):359-380.

3. Koivunen T. Gender in Call Centre Work. Acta Universitatis Tamperensis 1680. Tampere: Tampere University Press; 2011.

4. Star SL. Strauss, A. Layers of Silence, Arenas of Voice: The Ecology of Visible and Invisible Work. Computer Supported Cooperative Work. 1999;8:1-2,9-30.

5. Belt V, Richardson R. Webster J. Women's work in the information economy. Information, Communication \& Society, 2000;3(3):366-385.

6. Korvajärvi P. Gender and Work-Related Inequalities in Finland. In Devine F, Waters M. (eds) Social Inequalities in Comparative Perspective. Oxford: Blackwell Publishing; 2004.

7. Korvajärvi P. Locating Gender Neutrality in Formal and Informal Aspects of Organizational Cultures. Culture and Organization. 2002;8:(2)101-115.

8. Smith A, Organ D. Near, J. Organizational Citizenship Behavior: Its Nature and Antecedents. Journal of Applied Psychology. 1983;68(4):653-663.

9. Mayo E. The Social Problems of an Industrial Civilization. Boston: Harvard University; 1945. 
10. Roethlisberger FJ. Dickson WJ. Management and the Worker. Cambridge, Massachusetts: Harward University Press; 1949.

11. Schwartzman H. Ethnography in Organizations. Newbury Park: Sage; 1993.

12. Phakathi ST. "Getting on" and "Getting by" Underground. Gold Miners' Informal Working Practice of Making a Plan (planisa). Journal of Organizational Ethnography. 2013;2(2):126-149.

13. Acker J. Gendering Organizational Theory. In Mills A, Tancred P. (eds) Gendering Organizational Analysis, Newbury Park: Sage; 1992.

14. Connell R. Glass Ceilings or Gendered Institutions? Mapping the Gender Regimes of Public Sector Worksites. Public Administration Review. 2006;66(6):837849.

15. Veijola S, Jokinen E. Towards a Hostessing Society? Mobile Arrangements of Gender and Labour. NORA-Nordic Journal of Feminist and Gender Research. 2008;16(3):166-181.

16. Hochschild AR. The Managed Heart. Commercialization of Human Feeling. Second Edition. Berkeley: University of California Press; 1983/2003.

17. Guy ME. Newman, M. Women's Jobs, Men's Jobs: Sex Segregation and Emotional Labour. Public Administration Review. 2004;64(3):289-298.

18. Williams C. Sky Service: The Demands of Emotional Labour in the Airline Industry. Gender, Work \& Organization. 2003;10(5):513-550.

19. Hammersley M. Atkinson P. Ethnography. Principles in Practice. $2^{\text {nd }}$ Edition. London, Routledge; 1995.

20. Brewer J. Ethnography. Buckingham: Open University Press; 2000.

21. Van Maanen J. An End to Innocence: The Ethnography of Ethnography. In van Maanen J. (ed) Representation in Ethnography, London: Sage; 1995.

22. Emerson R, Fretz R. Shaw L. Participant Observation and Fieldnotes. In Atkinson,
P, Coffey A, Delamont S, Lofland J. Lofland L. (eds) Handbook of Ethnography, London: Sage; 2001.

23. Coffey A. The Ethnographic Self. Fieldwork and the Representation of Identity. London: Sage; 1999.

24. Richardson L. Writing: A Method of Inquiry. In Denzin N, Lincoln Y, (eds) Collecting and Interpreting Qualitative Materials. Thousand Oaks: Sage; 1998.

25. Henttonen E. An Ethnographic Study of Women's Small ITC Businesses in Finland. Acta Universitatis Oeconomicae Helsingiensis A-371. Helsinki: Aalto University School of Economics; 2010.

26. Poggio, B. Editorial: Outline of a Theory of Gender Practices. Gender, Work and Organization. 2006;13(3):225-233.

27. Martin PY. 'Said and Done' Versus 'Saying and Doing'. Gendering Practices, Practicing Gender at Work. Gender \& Society. 2003;1(3):342-366.

28. West C. Zimmerman, D. Doing Gender. Gender \& Society. 1987;1(2):125-151.

29. Fletcher J. Disappearing Acts: Gender, Power and Relational Practice at Work. Cambridge: The MIT Press; 2001.

30. Ikonen HM, Ojala $H$. Creating Togetherness and Experiencing Difference in Feminist Interviews - Knowing in a poststandpoint way? Graduate Journal of Social Science. 2007;4(2):80-103.

31. Bruni, A. 'Have You Got a Boyfriend or are You Single?': On the Importance of Being 'Straight' in Organizational Research. Gender, Work and Organization. 2006;13(3):299-316.

32. Belt V, Richardson R. Webster, J. Women, social skill and interactive service work in telephone call centres. New Technology, Work and Employment. 2002;17(1):20-34.

33. Korvajärvi P. Women and technological pleasure at work? In Heiskanen T, Hearn J. (eds) Information Society and the Workplace. Spaces, Boundaries and Agency, London: Routledge; 2004.

(C) 2016 Koivunen; This is an Open Access article distributed under the terms of the Creative Commons Attribution License (http://creativecommons.org/licenses/by/4.0), which permits unrestricted use, distribution, and reproduction in any medium, provided the original work is properly cited.

Peer-review history:

The peer review history for this paper can be accessed here: http://sciencedomain.org/review-history/11893 